\title{
Discovery of Small Molecule Mer Kinase Inhibitors for the Treatment of Pediatric Acute Lymphoblastic Leukemia
}

\author{
Jing Liu, ${ }^{\dagger, \|}$ Chao Yang, ${ }^{\dagger, \|}$ Catherine Simpson, ${ }^{\dagger}$ Deborah DeRyckere, ${ }^{\perp}$ Amy Van Deusen, ${ }^{\dagger}$
} Michael J. Miley, ${ }^{\S}$ Dmitri Kireev, ${ }^{\dagger}$ Jacqueline Norris-Drouin ${ }^{\dagger}$ Susan Sather, ${ }^{\perp}$ Debra Hunter, ${ }^{\dagger}$ Victoria K. Korboukh, ${ }^{\dagger}$ Hari S. Patel, ${ }^{\dagger}$ William P. Janzen, ${ }^{\dagger}$ Mischa Machius, ${ }^{\S}$ Gary L. Johnson, ${ }^{\S, \downarrow}$ H. Shelton Earp, ${ }^{\ddagger, \&}$ Douglas K. Graham, ${ }^{\perp}$ Stephen V. Frye, ${ }^{\dagger, \$}$ and Xiaodong Wang, ${ }^{* \dagger}$

${ }^{\dagger}$ Center for Integrative Chemical Biology and Drug Discovery, Division of Chemical Biology and Medicinal Chemistry, Eshelman School of Pharmacy, ${ }^{\S}$ Department of Pharmacology, ${ }^{\star}$ Lineberger Comprehensive Cancer Center, Department of Medicine, School of Medicine, University of North Carolina at Chapel Hill, Chapel Hill, North Carolina 27599, United States

${ }^{\perp}$ Department of Pediatrics, School of Medicine, University of Colorado Denver, Aurora, Colorado 80045, United States

\section{Supporting Information}

ABSTRACT: Ectopic Mer expression promotes pro-survival signaling and contributes to leukemogenesis and chemoresistance in childhood acute lymphoblastic leukemia (ALL). Consequently, Mer kinase inhibitors may promote leukemic cell death and further act as chemosensitizers increasing efficacy and reducing toxicities of current ALL regimens. We have applied a structure-based design approach to discover novel small molecule Mer kinase inhibitors. Several pyrazolopyrimidine derivatives effectively inhibit Mer kinase activity at subnanomolar concentrations. Furthermore, the lead compound shows a promising selectivity profile against a panel of 72 kinases and has excellent pharmacokinetic properties. We also describe the crystal structure of the complex between the lead compound and Mer, opening new opportunities for further optimization and new template design.

KEYWORDS: Mer inhibitors, acute lymphoblastic leukemia, pyrazolopyrimidines, chemosensitizer

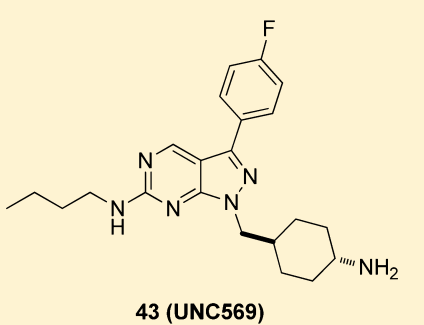

43 (UNC569)
A cute lymphoblastic leukemia (ALL) is the most common malignancy in children and represents nearly $30 \%$ of all pediatric cancers. ${ }^{1}$ Although most childhood ALL types are curable, T-cell ALL, a subtype that accounts for $10-15 \%$ of pediatric ALL cases, has a poorer prognosis, with a 5-year relapse-free survival rate of $60-75 \%$ even with effective treatment. ${ }^{2}$ Extensive exposure to current chemotherapeutic regimens is associated with toxic side effects (growth slowing, organ damage, and secondary malignancy) and development of chemoresistance. ${ }^{3}$

Previous studies have indicated a role for Mer receptor tyrosine kinase (RTK) in ALL. Mer is ectopically expressed in at least $50 \%$ of pediatric T-cell ALL samples as well as in pre-B ALL samples, particularly those with a $(1 ; 19)(\mathrm{q} 23 ; \mathrm{p} 13)$ translocation encoding an E2A/PBX1 fusion protein., ${ }^{1,5}$ In contrast, Mer is not expressed in normal mouse and human $\mathrm{T}$ and B-lymphocytes at any stage of development. This tumor specific expression pattern may confer a wide therapeutic window-at least in these cell types. In previous studies, transgenic expression of Mer in mouse lymphocytes resulted in development of T-cell leukemias and lymphomas. ${ }^{6}$ In addition, a Mer expressing human B-ALL cell line was able to produce a lethal malignancy in immunocompromised mice; development of leukemia was significantly delayed or completely eliminated by Mer shRNA knockdown in these cells. ${ }^{3}$ Mer also contributes to lymphoblast chemoresistance. For example, Mer transgenic lymphocytes have a statistically significant survival advantage relative to wild-type lymphocytes when treated with dexamethasone, a critical component of ALL induction chemotherapy. In human ALL cell lines, Mer expression also mediates resistance to other commonly used ALL chemotherapeutics (vincristine, 6-mercaptopurine, methotrexate, and doxorubicin). ${ }^{3}$ Taken together, these data provide a rationale for development of Mer kinase inhibitors as selective therapeutics for ALL and other Mer related diseases. In addition, these inhibitors may mediate synergistic antileukemia activity in combination with standard chemotherapy, thereby permitting dose reduction and diminished toxic side effects.

Mer is a member of the TAM (Tyro3, Axl, Mer) RTK family. Each member of the TAM family contains an extracellular domain, a transmembrane domain, and a conserved intracellular kinase domain., ${ }^{4,7}$ Compared with other tyrosine kinases, the intracellular kinase domain of the TAM family is quite dissimilar (40\% sequence identity). This makes Mer an excellent candidate for targeting selectively by small molecules. To date, only one weak Mer inhibitor, Compound-52 ( $\mathrm{IC}_{50}=$ $11 \mu \mathrm{M}$ ) (Figure 1a), has been reported, and the crystal structure of its complex with Mer has been determined at 2.8 A. ${ }^{8}$ Although Compound-52 is not valuable for further drug development due to its limited potency and lack of selectivity,

Received: October 20, 2011

Accepted: January 9, 2012

Published: January 9, 2012 
<smiles>CC(C)n1cnc2c(Nc3cccc(Cl)c3)nc(NCCO)nc21</smiles>

Compound-52

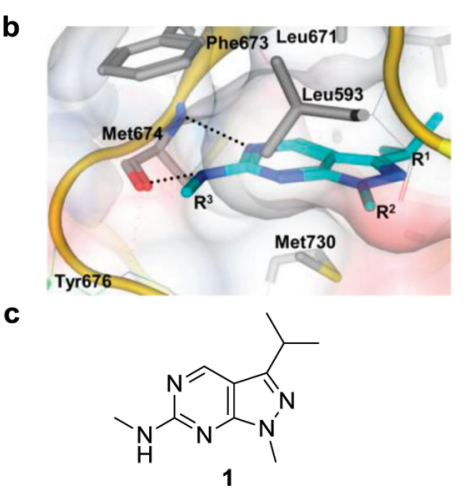

d<smiles>[R]Nc1ncc2c([R])n[nH]c2n1</smiles>

$\mathrm{R}^{1}=$ alkyl, alkene, $\mathrm{Ar}$

$R^{2}=\gamma^{n} n=0,1,2$

$\mathrm{R}^{\prime} \mathrm{R}^{\prime}=\mathrm{OH}, \mathrm{NH}_{2}$, etc.

$\mathrm{NH}_{\mathrm{nH}} \mathrm{n}=0,1,2$

$\mathbf{R}^{3}=$ substituted alkyl chains

Figure 1. (a) Chemical structure of Compound-52; (b) docking model of $\mathbf{1}$ in the X-ray structure of Mer; (c) chemical structure of 1; (d) design of candidate Mer kinase inhibitors based on the pyrazolopyrimidine scaffold.

Scheme 1. Synthetic Routes for the Pyrazolopyrimidine Scaffold<smiles>CSc1ncc2c(=O)[nH][nH]c2n1</smiles>

2

$\mathrm{R}^{1}, \mathrm{R}^{2}, \mathrm{R}^{3}=$ alkyl, alkenyl aryl, or heteroaryl, etc.<smiles>[R]n1nc(Br)c2cnc(SC)nc21</smiles>

3

path a $\mid \begin{aligned} & \mathrm{R}^{1} \mathrm{~B}(\mathrm{OH})_{2}, \\ & \mathrm{Pd}\left(\mathrm{PPh}_{3}\right)_{4}, \\ & \mathrm{~K}_{2} \mathrm{CO}_{3}\end{aligned}$<smiles>[R]c1n[nH]c2nc(SC)ncc12</smiles>

4
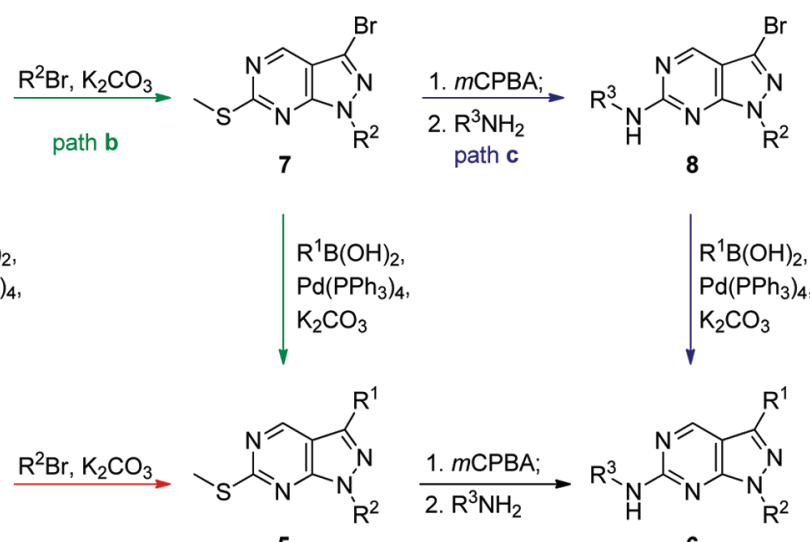

5

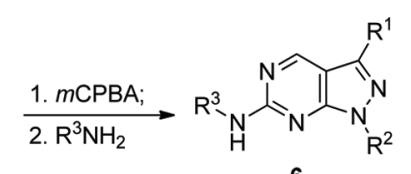

the crystal structure provided an opportunity to develop Mer inhibitors using structure-based drug design.

On the basis of the crystal structure of Compound-52 with Mer, a pyrazolopyrimidine heterocycle (1, Figure 1b, 1c) was proposed. This molecule occupied the adenine pocket, formed two hydrogen bonds with the hinge-backbone Met674, and was stabilized within a lipophilic cage formed by Leu593, Phe673, and Met730. In addition, its isopropyl group pointed toward the activation loop. The structural features of $\mathbf{1}$ also enabled at least three sites $\left(R^{1}, R^{2}\right.$, and $R^{3}$ ) (Figure $1 d$ ) for facile modification to optimize the inhibitory potency, selectivity, and bioavailability. Furthermore, pyrazolopyrimidines are popular synthetic pharmacophores and have been explored as ATP competitive inhibitors of kinases. ${ }^{9-20}$ The substituents at the $\mathrm{R}^{1}, \mathrm{R}^{2}$, and $\mathrm{R}^{3}$ positions were chosen by considering their basic chemical features. For instance, polar substituents of various sizes at the $\mathrm{R}^{2}$ substitution site were expected to form an ionic bond and/or hydrogen bond with Asp678. At the $\mathrm{R}^{1}$ and $\mathrm{R}^{3}$ positions, a variety of groups would be tested.

We have developed an efficient route to prepare pyrazolopyrimidine analogues (Scheme 1). The key intermediate 3 was synthesized from bromination of the known compound 2 with phosphoryl tribromide $\left(\mathrm{POBr}_{3}\right)$ in a sealed tube. ${ }^{21}$ In path a, Suzuki coupling between 3 and a boronic acid provided 4, which was subsequently alkylated at the $\mathrm{N} 1$ position of the pyrazole ring to yield $5 .^{22} 3$-Chlorobenzoperoxoic acid ( $m$ CPBA) oxidation followed by the displacement of the methyl sulfinyl/sulfonyl group by amines then provided the final pyrazolopyrimidine analogue $6 .^{23}$ This sequence of reactions (path a) is ideal for exploration of structure-activity relationships (SAR) at the $\mathrm{R}^{2}$ and $\mathrm{R}^{3}$ positions. The three reactions (Suzuki coupling, alkylation, and oxidation $/ S_{N} A r$ displacement) in path a can be carried out in varying order to optimally explore SAR at different positions. Accordingly, path $\mathrm{b}(3 \rightarrow 7 \rightarrow 5 \rightarrow 6)$ is more suitable for modifications at the $\mathrm{R}^{3}$ position while path $\mathrm{c}(3 \rightarrow 7 \rightarrow 8 \rightarrow 6)$ is preferable when multiple analogues with variation at the $\mathrm{R}^{1}$ group are required.

To gain initial information on SAR at the $R^{1}$ and $R^{2}$ substitution sites, a small compound library with $\mathrm{R}^{3}$ fixed as the MeNH group was synthesized via path $\mathrm{c}$ in Scheme 1 . Inhibition of Mer kinase activity by analogues was tested at the ATP $\mathrm{Km}$ using a microfluidic capillary electrophoresis (MCE) assay $^{24-26}$ in which phosphorylated and unphosphorylated substrate peptides were separated and analyzed through a LabChip EZ Reader. Representative examples from this library are shown in Table 1. For Mer activity, the order of preferred substituents at the $\mathrm{R}^{1}$ position is aryl > alkenyl > alkyl $(9,13$, and 14). For the $\mathrm{R}^{2}$ position, the distance between the pyrazole ring and the polar group on $\mathrm{R}^{2}$ is important, and a parasubstituted cyclohexylmethyl group was preferred (9-12). Although trans- and cis-4-hydroxylcyclohexylmethyl analogues 14 and 15 were equally potent for inhibition of Mer kinase activity, trans-4-aminocyclohexylmethyl analogue 16 was 3-fold more potent than the cis-analogue 17. Activity against Axl and Tyro3 was also determined to monitor their selectivity within the TAM family and develop a pan-TAM SAR. In general, these analogues showed modest selectivity within the TAM family. They are generally less potent against Tyro3 (>5-fold) while there is little difference in the activities between Mer and Axl. 
Table 1. Preliminary SAR at the $R^{1}$ and $R^{2}$ Positions

12

${ }^{a}$ Values are the mean of two or more independent assays performed at the ATP $K_{\mathrm{m}} \cdot{ }^{b}$ Is a racemate.

With 4-aminocylcohexylmethyl selected as an optimized $\mathrm{R}^{2}$ group on the basis of in vitro potency, the effect of substitution on the phenyl ring at the $\mathrm{R}^{1}$ position was then explored (Table 2). The para-methoxyl substituted analogue $\mathbf{1 8}$ was 5 -fold more potent than meta substituted 19 and 56-fold more potent than ortho substituted 20. In addition, the chemical properties of the substituents have a significant effect on Mer kinase inhibition. In general, electron withdrawing groups decreased activity, while electron donating groups increase activity. For example, compound 18 (para-methoxyl) was 7-fold more potent than $\mathbf{2 1}$ (para- $\left.\mathrm{CF}_{3}\right)$. The introduction of a phenyl group at the para position (22) slightly decreased the activity compared to that of 18. 3-Pyridyl (23) and 6-F-3-pyridyl (24) as the $\mathrm{R}^{1}$ substituents were also less active than 16. However, introduction of a piperidine ring at the 6-position of the 3-pyridyl provided a very potent compound, 25. Replacement of the pyridine ring with the more hydrophobic phenyl ring further increased the potency by 4-fold (26). These results suggest that electrondonating, para-substituted phenyl or pyridinyl groups are suitable $\mathrm{R}^{1}$ substitutions.

As shown in Table 2, the secondary amine $(\mathrm{NH})$ at the $\mathrm{R}^{3}$ position was critical for potency due to a hydrogen bond
Table 2. SAR Study of $R^{1}$ and $R^{3}$<smiles>[R]c1ncc2c([R])nn(CC3CCC(N)CC3)c2n1</smiles>

\begin{tabular}{|c|c|c|c|c|c|}
\hline \multirow[t]{2}{*}{ Compound $^{a}$} & \multirow[t]{2}{*}{$\mathrm{R}^{1}$} & \multirow[t]{2}{*}{$\mathrm{R}^{3}$} & \multicolumn{3}{|c|}{$\mathrm{IC}_{50}(\mu \mathrm{M})^{b}$} \\
\hline & & & Mer & Axl & Tyro3 \\
\hline 18 & & $-\stackrel{H}{N-\xi}-$ & 0.025 & 0.036 & 0.41 \\
\hline 19 & & $-\mathrm{H}-\hat{\mathrm{N}}-$ & 0.12 & 0.15 & 1.5 \\
\hline 20 & & $-\stackrel{H}{N-\xi}-$ & 1.40 & 0.69 & 11 \\
\hline 21 & & $-\stackrel{H}{N-\xi}-$ & 0.17 & 0.22 & 2.1 \\
\hline 22 & & $-\mathrm{H}-\underline{-}-$ & 0.056 & 0.05 & 0.12 \\
\hline 23 & & $-\mathrm{H} \cdot \hat{\mathrm{s}}-$ & 0.53 & 0.75 & 5.4 \\
\hline 24 & & $-\mathrm{H} \cdot \hat{\mathrm{s}}-$ & 0.40 & 0.61 & 4.3 \\
\hline 25 & & $-\stackrel{H}{N-\xi}-$ & 0.064 & 0.057 & 0.64 \\
\hline 26 & & & 0.018 & 0.014 & 0.26 \\
\hline 27 & & $\lambda^{N-\xi-1}$ & 2.8 & 22 & 75 \\
\hline 28 & & & 0.013 & 0.18 & 0.08 \\
\hline 29 & & & 0.0058 & 0.10 & 0.071 \\
\hline 30 & & & 0.014 & 0.047 & 0.077 \\
\hline 31 & & & 0.074 & 1.4 & 0.37 \\
\hline 32 & & & 0.062 & 0.36 & 0.45 \\
\hline 33 & & & 0.14 & 0.66 & 0.25 \\
\hline 34 & & & 4.5 & 17 & 17 \\
\hline 35 & & & 0.0082 & 0.038 & 0.075 \\
\hline 36 & & & 0.010 & 0.059 & 0.34 \\
\hline 37 & & & 0.013 & 0.041 & 0.018 \\
\hline 38 & & & 0.010 & 0.038 & 0.37 \\
\hline
\end{tabular}

${ }^{a}$ Is a 2:1 mixture of cis/trans isomers. ${ }^{b}$ Values are the mean of two or more independent assays performed at the ATP $K_{\mathrm{m}}$.

formed with the hinge region of the protein. Replacement of the secondary amine with a tertiary amine greatly decreased activity (27). Extension of the alkyl chain $(\mathrm{C} 3-\mathrm{C5})$ at the $\mathrm{R}^{3}$ site boosted the potency of the analogues $(28-30)$ while a branched alkyl chain (31) and cycloalkyl groups (32) were less favorable. Introducing polar groups into the alkyl chain decreased the activity of the analogues dramatically (33 and 34). However, a phenyl ring or a simple para-substituted phenyl ring was well tolerated at this position (35-38). Varying the $\mathrm{R}^{3}$ group affected not only the analogues' activity toward Mer but also the selectivity within the TAM family members. The best selectivity was achieved by analogue $\mathbf{2 9}$, which has 17-fold selectivity for Mer over Axl and 12-fold selectivity for Mer over Tyro3.

Upon completion of the SAR studies in Tables 1 and 2, we next decided to synthesize a small focused library of six 
Table 3. Focused Library

49

compounds with a "mix and match" combination of the optimal substituents at the $\mathrm{R}^{1}$ and $\mathrm{R}^{3}$ positions (Table 3 ). Indeed, this exercise turned out to be highly productive, as all six compounds show potent inhibition of Mer kinase activity, with $\mathrm{IC}_{50}$ values in the range $0.15-3.0 \mathrm{nM}$.

These analogues are more active against Mer than Axl and Tyro3. The inhibition constants $\left(K_{\mathrm{i}}\right)$ of these analogues for Mer were also determined (Table 3). As anticipated, these compounds were also shown to be ATP competitive inhibitors (details in the Supporting Information). The most active compound, 42, and the low molecular weight compound, 43 (UNC569), were also profiled against 72 kinases (details in the Supporting Information) including the TAM family members using the same MCE assay. This panel of kinases provides a general survey of kinase families and coverage of the TAM and closely related MET family. Tested in duplicate at a concentration 10-fold higher than its $\mathrm{IC}_{50}$ value against Mer, both 42 and 43 inhibited only three other kinases by greater than 50\%: FLT3 (82\% and 82\%, respectively), MAPKAPK2
(94\% and 92\%, respectively), Ret (79\% and 59\%, respectively), and its mutant Ret Y791F ( $67 \%$ and 56\%, respectively).

In addition, a cocrystal structure of Mer in complex with 43 was determined at a resolution of $2.69 \AA$. The structure highlights an unanticipated binding mode (see Figure 2). The inhibitor, including its flexible lipophilic substituent $\mathrm{R}^{3}$, is fully confined to a relatively small adenine pocket instead of protruding into the lipophilic back-pocket. This binding mode is probably determined by the following structural features of Mer. First, Mer has a relatively large gatekeeper residue (Leu671). It also forms the "gate" to the back-pocket with another four residues (Ile650, Ala740, Asp741, and Lys619) (Figure 2). The two residues Leu671 and Ile650 situated on the loop connecting the $\alpha \mathrm{C}$ helix to the $\beta 4$ strand (right below the gatekeeper) render the lipophilic back-pocket inaccessible to inhibitors. It is also noteworthy that one of the gate-forming residues, Ile650, is not conserved among the TAM family members. Hence, this pocket area might be instrumental for Mer inhibitor selectivity toward Axl and Tyro3, which feature methionine and alanine, respectively, in this position. 


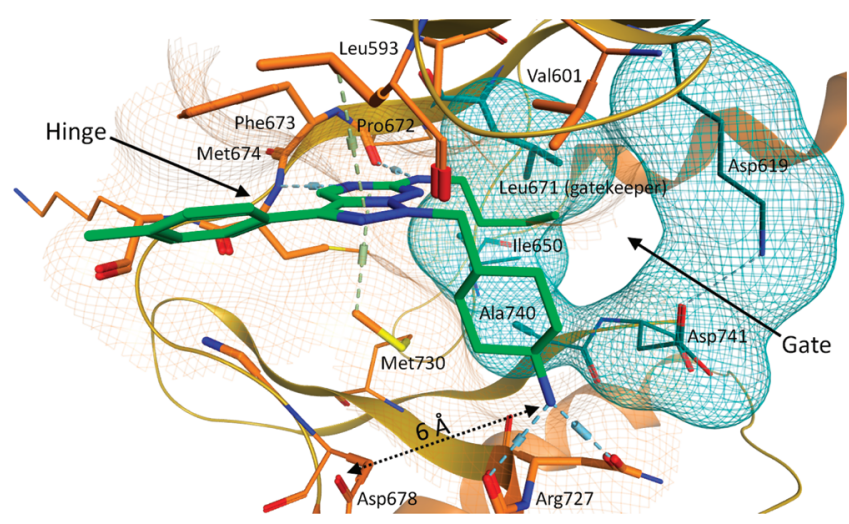

Figure 2. X-ray crystal structure of $\mathbf{4 3}$ in complex with Mer (kinase domain). The surface of the adenine pocket is outlined in brown mesh. The molecular surface of five residues constituting a "gate" to the backpocket is shown in cyan mesh.

The $\mathrm{R}^{2}$ substituent occupies the ATP sugar pocket with its amino group forming a hydrogen bond with the carbonyl of Arg727. Again, this represents a counterintuitive interaction given that the ionized amino nitrogen could have formed an energetically stronger interaction with Asp678, as is the case for the inhibitor Compound-52. ${ }^{8}$ Finally, the $\mathrm{R}^{1}$ substituent interacts mostly with the solvent and can be exploited for tuning solubility and other pharmacokinetic properties. The information acquired from this structure opens new opportunities for further optimization of inhibitory potency and pharmacokinetic properties of the current series.

Furthermore, the ability of $\mathbf{4 3}$ to inhibit Mer autophosphorylation in human B-ALL cells was tested. Human Pre-B leukemia 697 cells were treated with various concentrations of 43 for $1 \mathrm{~h}$ prior to addition of a phosphatase inhibitor to stabilize phospho-Mer. Mer protein was immunoprecipitated from lysates, and phospho-Mer was detected by Western blot using a rabbit polyclonal antibody raised against a triphosphorylated Mer peptide. Phospho-Mer levels were quantitated by densitometry, and $\mathrm{IC}_{50}$ values were determined using nonlinear regression. In this cell-based assay, the $\mathrm{IC}_{50}$ for inhibition of phospho-Mer by 43 was $141 \mathrm{nM}$.

The in vivo pharmacokinetic (PK) properties of 43 were also assessed in mice via both intravenous (IV) and oral (PO) administration (details in the Supporting Information). 43 had low systemic clearance $(19.5 \mathrm{~mL} / \mathrm{min} / \mathrm{kg})$, high volume of distribution $\left(V_{\mathrm{ss}}=5.83 \mathrm{~L} / \mathrm{kg}\right)$, and good oral bioavailability (57\%).

In conclusion, we have successfully developed a robust SAR and discovered potent small molecule Mer inhibitors within the pyrazolopyrimidine scaffold. A cocrystal structure of Mer with the lead compound $\mathbf{4 3}$ has also been determined and reveals an unusual binding mode in the catalytic kinase domain. The selectivity and DMPK properties of the lead compound are very promising, suggesting it is a viable lead candidate for optimization toward Mer inhibitors for clinical applications.

\section{ASSOCIATED CONTENT}

\section{S Supporting Information}

Experimental details and characterization of all compounds and biological methods. This material is available free of charge via the Internet at http://pubs.acs.org.

\section{Accession Codes}

The atomic coordinates for the X-ray crystal structure of $\mathbf{4 3}$ have been deposited with the RCSB Protein Data Bank under the accession code 3TCP.

\section{AUTHOR INFORMATION}

\section{Corresponding Author}

*Telephone: 919-843-8456. Fax: 919-843-8465. E-mail: xiaodonw@unc.edu.

\section{Author Contributions}

"These authors contributed equally.

\section{Funding}

This work was supported by the University Cancer Research Fund, School of Pharmacy, Carolina Partnership, the University Research Council at University of North Carolina, and Federal Funds from the National Cancer Institute, National Institute of Health, under Contract No. HHSN261200800001E. The content of this publication does not necessarily reflect the views or policies of the Department of Health and Human Services, nor does mention of trade names, commercial products, or organizations imply endorsement by the U.S. Government. Use of the Advanced Photon Source was supported by the U.S. Department of Energy, Office of Science, Office of Basic Energy Sciences, under Contract No. W-31-109-Eng-38.

\section{Notes}

The authors declare no competing financial interest.

\section{ACKNOWLEDGMENTS}

We thank Professor Sirano Dhe-Paganon, Structural Genomics Consortium, University of Toronto, for providing the Mer kinase domain expression construct and Professor K. H. Lee's lab at UNC for HRMS support.

\section{REFERENCES}

(1) Graham, D. K.; Salzberg, D. B.; Kurtzberg, J.; Sather, S.; Matsushima, G. K.; Keating, A. K.; Liang, X.; Lovell, M. A.; Williams, S. A.; Dawson, T. L.; Schell, M. J.; Anwar, A. A.; Snodgrass, H. R.; Earp, H. S. Ectopic expression of the proto-oncogene Mer in pediatric T-cell acute lymphoblastic leukemia. Clin. Cancer Res. 2006, 12 (9), 2662-9.

(2) Pui, C. H.; Relling, M. V.; Downing, J. R. Acute lymphoblastic leukemia. N. Engl. J. Med. 2004, 350 (15), 1535-48.

(3) Linger, R. M.; Deryckere, D.; Brandao, L.; Sawczyn, K. K.; Jacobsen, K. M.; Liang, X.; Keating, A. K.; Graham, D. K. Mer receptor tyrosine kinase is a novel therapeutic target in pediatric B-cell acute lymphoblastic leukemia. Blood 2009.

(4) Linger, R. M. A.; Keating, A. K.; Earp, H. S.; Graham, D. K. TAM Receptor Tyrosine Kinases: Biologic Functions, Signaling, and Potential Therapeutic Targeting in Human Cancer. In Advanced Cancer Research; Academic Press: New York, 2008; Vol. 100, pp 3583.

(5) Graham, D. K.; Dawson, T. L.; Mullaney, D. L.; Snodgrass, H. R.; Earp, H. S. Cloning and mRNA expression analysis of a novel human protooncogene, c-mer. Cell Growth Differ. 1994, 5 (6), 647-57.

(6) Keating, A. K.; Salzberg, D. B.; Sather, S.; Liang, X.; Nickoloff, S.; Anwar, A.; Deryckere, D.; Hill, K.; Joung, D.; Sawczyn, K. K.; Park, J.; Curran-Everett, D.; McGavran, L.; Meltesen, L.; Gore, L.; Johnson, G. L.; Graham, D. K. Lymphoblastic Leukemia/lymphoma in Mice Overexpressing the Mer (MerTK) Receptor Tyrosine Kinase. Oncogene 2006, 25 (45), 6092-6100.

(7) Lemke, G.; Rothlin, C. V. Immunobiology of the TAM receptors. Nat. Rev. Immunol. 2008, 8 (5), 327-36. 
(8) Huang, X.; Finerty, P. Jr.; Walker, J. R.; Butler-Cole, C.; Vedadi, M.; Schapira, M.; Parker, S. A.; Turk, B. E.; Thompson, D. A.; DhePaganon, S. Structural insights into the inhibited states of the Mer receptor tyrosine kinase. J. Struct. Biol. 2009, 165 (2), 88-96.

(9) Chen, W.; Loury, D. J.; Mody, T. D. Preparation of pyrazolopyrimidine compounds as inhibitors of Bruton's tyrosine kinase. US7718662B1, 2010.

(10) Traxler, P.; Bold, G.; Frei, J.; Lang, M.; Lydon, N.; Mett, H.; Buchdunger, E.; Meyer, T.; Mueller, M.; Furet, P. Use of a Pharmacophore Model for the Design of EGF-R Tyrosine Kinase Inhibitors: 4-(Phenylamino)pyrazolo[3,4-d]pyrimidines. J. Med. Chem. 1997, 40 (22), 3601-3616.

(11) Gilbert, A. M.; Nowak, P.; Brooijmans, N.; Bursavich, M. G.; Dehnhardt, C.; Santos, E. D.; Feldberg, L. R.; Hollander, I.; Kim, S.; Lombardi, S.; Park, K.; Venkatesan, A. M.; Mallon, R. Novel purine and pyrazolo[3,4-d]pyrimidine inhibitors of PI3 kinase-[alpha]: Hit to lead studies. Bioorg. Med. Chem. Lett. 2010, 20 (2), 636-639.

(12) Kaplan, J.; Verheijen, J. C.; Brooijmans, N.; Toral-Barza, L.; Hollander, I.; Yu, K.; Zask, A. Discovery of 3,6-dihydro-2H-pyran as a morpholine replacement in 6-aryl-1H-pyrazolo[3,4-d]pyrimidines and 2-arylthieno[3,2-d]pyrimidines: ATP-competitive inhibitors of the mammalian target of rapamycin (mTOR). Bioorg. Med. Chem. Lett. 2010, 20 (2), 640-643.

(13) Kim, D. C.; Lee, Y. R.; Yang, B.-S.; Shin, K. J.; Kim, D. J.; Chung, B. Y.; Yoo, K. H. Synthesis and biological evaluations of pyrazolo[3,4-d]pyrimidines as cyclin-dependent kinase 2 inhibitors. Eur. J. Med. Chem. 2003, 38 (5), 525-532.

(14) Schenone, S.; Bruno, O.; Ranise, A.; Bondavalli, F.; Brullo, C.; Fossa, P.; Mosti, L.; Menozzi, G.; Carraro, F.; Naldini, A.; Bernini, C.; Manetti, F.; Botta, M. New pyrazolo[3,4-d]pyrimidines endowed with A431 antiproliferative activity and inhibitory properties of Src phosphorylation. Bioorg. Med. Chem. Lett. 2004, 14 (10), 2511-2517. (15) Lourido, S.; Shuman, J.; Zhang, C.; Shokat, K. M.; Hui, R.; Sibley, L. D. Calcium-dependent protein kinase 1 is an essential regulator of exocytosis in Toxoplasma. Nature 2010, 465 (7296), 35962 .

(16) Islam, K.; Chin, H. F.; Olivares, A. O.; Saunders, L. P.; De La Cruz, E. M.; Kapoor, T. M. A myosin V inhibitor based on privileged chemical scaffolds. Angew. Chem., Int. Ed. Engl. 2010, 49 (45), 8484-8.

(17) Revesz, L. Preparation of pyrazolo-heteroaryl compounds for inhibiting TNF-alpha production. WO2006063820A1, 2006.

(18) Revesz, L.; Blum, E.; Di, P. F. E.; Buhl, T.; Feifel, R.; Gram, H.; Hiestand, P.; Manning, U.; Neumann, U.; Rucklin, G. Pyrazoloheteroaryls: Novel p38 $\alpha$ MAP kinase inhibiting scaffolds with oral activity. Bioorg. Med. Chem. Lett. 2006, 16 (2), 262-266.

(19) Kasibhatla, S. R.; Hong, K.; Zhang, L.; Boehm, M. F.; Fan, J.; Le, B. J.-Y. Pyrazolopyrimidine derivatives as mitotic kinases modulators and their preparation, pharmaceutical compositions and use in the treatment of cancer. WO2008094602A2, 2008.

(20) Ding, Q.; Jiang, N.; Roberts, J. L. Preparation of pyrazolopyrimidines as antitumor agents. US20050277655A1, 2005.

(21) Liu, J.; Wang, X. Microwave-Assisted, Divergent Solution-Phase Synthesis of 1,3,6-Trisubstituted Pyrazolo[3,4-d]pyrimidines. ACS Comb. Sci. 2011, 13 (4), 414-420.

(22) Klein, M.; Diner, P.; Dorin-Semblat, D.; Doerig, C.; Grotli, M. Synthesis of 3-(1,2,3-triazol-1-yl)- and 3-(1,2,3-triazol-4-yl)-substituted pyrazolo[3,4-d]pyrimidin-4-amines via click chemistry: potential inhibitors of the Plasmodium falciparum PfPK7 protein kinase. Org. Biomol. Chem. 2009, 7 (17), 3421-3429.

(23) Southon, I. W.; Pfleiderer, W. Untersuchungen in der Pyrimidinreihe, XXX: Synthese und Eigenschaften von Pyrimidinsulfoxiden, -sulfonen und -nitraminen. Chem. Ber. 1978, 111 (3), 1006-1018.

(24) Pommereau, A.; Pap, E.; Kannt, A. Two simple and generic antibody-independent kinase assays: comparison of a bioluminescent and a microfluidic assay format. J. Biomol. Screening 2004, 9 (5), 40916.
(25) Dunne, J.; Reardon, H.; Trinh, V.; Li, E.; Farinas, J. Comparison of on-chip and off-chip microfluidic kinase assay formats. Assay Drug Dev. Technol. 2004, 2 (2), 121-9.

(26) Bernasconi, P.; Chen, M.; Galasinski, S.; Popa-Burke, I.; Bobasheva, A.; Coudurier, L.; Birkos, S.; Hallam, R.; Janzen, W. P. A chemogenomic analysis of the human proteome: application to enzyme families. J. Biomol. Screening 2007, 12 (7), 972-82. 